\title{
Participative Management in Relation to Library Effectiveness
}

This paper reviews a recent study on the influence of participative management on library performance. Because most of the recent theoretical and empirical research being done in this area is ignored and an invalid measure of participation in decision making is used, the study provides no basis for the generalization that an increase in the library staff's participation in decision making will increase the library's effectiveness.

I F RESEARCH IN LIBRARIANSHIP is to progress toward its objective of "extending the existing body of factual knowledge concerning the values and procedures of libraries in their many aspects," researchers must make every appropriate use of insights, concepts, and methods of other disciplines. ${ }^{1}$ One advantage of the affiliation of library schools with universities is that it facilitates the use of theories developed in other fields. The library researcher who borrows a theory, however, must fully understand its assumptions and limitations and must be thoroughly familiar with the empirical evidence which tends to support or to limit the application of the theory to the problems of librarianship. Naive or uninformed use of approaches found useful in other disciplines can be damaging, particularly if library administrators act on the basis of the invalid generalization. It is therefore important that studies that borrow from other fields be monitored critically so

Ms. Lynch is the newly appointed executive secretary of the Association of College and Research Libraries. At the time this paper was written she was a visiting lecturer at the University of Wisconsin Library School, Madison. that only well-founded research will be accepted.

This paper examines a study by Maurice P. Marchant, entitled, "Participative Management as Related to Personnel Development," which is based upon his dissertation, "The Effects of the Decision Making Process and Related Organizational Factors on Alternative Measures of Performance in University Libraries."2 Marchant's investigation was designed to measure the influence of the professional librarian's participation in decision making upon the library's effectiveness. Although Marchant found no statistically significant relationships between these variables, he reports significant relationships between participation in decision making and staff satisfaction.

Marchant borrows theory from behavioral science and deals with a subject which is of current interest to librarianship. His study is likely to be cited in library literature as evidence for the desirability of change in managerial style. Marchant's work is better than many recent studies on library organization and management in its structure, reporting, and use of statistical methods, but it reflects an insufficient knowledge of the theoretical and empirical work which has been done in 
participative management. There are also several faults in method and data analysis.

\section{The TheORY}

The major theoretical basis for Marchant's work stems from Rensis Likert's theory of participative management, which was presented in Likert's New Patterns of Management and then elaborated in his The Human Organization. $^{3}$ According to Likert a work group that accepts the "principle of supportive relationships" will achieve a higher rate of productivity than one that does not. Likert relies heavily for support of this theory on the experiment conducted by Morse and Reimer in four clerical divisions of a large company over a period of a year. ${ }^{4}$ Morse and Reimer report significant increases in productivity for both "participative" and "hierarchical" units, with a slightly higher increase in the hierarchically controlled division. Despite these contrary results the researchers felt that over a longer period of time the adverse effects on morale, which they observed in the hierarchial groups, would reduce their productivity. They assumed, however, that no self-corrective measures would be introduced into the hierarchial groups as production fell.

According to two recent comprehensive reviews research results relating participative management to productivity have been inconclusive..$^{5}$ Day and Hamblin report democratic supervision to be more effective, while Shaw reports authoritarian treatment to be more effective. ${ }^{6}$ Studies by McCurdy and Eber, Sales, and Spector and Suttell, indicate no relationship between leadership styles and productivity. ${ }^{7}$ Current research in a government organization fails to support a positive relationship of participative management to productivity. ${ }^{8}$ Furthermore, Carey, Korman, and Vroom have suggested that studies which consider the causal effect of managerial style on subordinate perform- ance can be interpreted as measuring the reverse effect, that is, the impact of performance on managerial style. ${ }^{9}$ More recently, another experiment provides strong evidence to support this hypothesis. ${ }^{10}$ It confirms an earlier study which reported that organizational behaviors are sensitive to prior organizational effectiveness. ${ }^{11}$

Vroom and Mann, French et al., Foa, Gibb, Patchen, and Pelz suggest that the effects of participative management on productivity may depend upon what exactly is being measured in the study, participative supervision, considerate supervision, or closeness of supervision, and upon the needs and expectations of subordinates. ${ }^{12}$ These studies suggest that a participative, considerate, or supportive leadership style may be most effective when the decisions are nonroutine in nature, when the information required for effective decision making cannot be centralized nor standardized, or when, because rapid decision making is not required, there is time for subordinates to be involved in the process. Whether subordinates feel a need for independence, regard their participation in decision making as legitimate, consider themselves capable of contributing to the decision making, or are confident enough to work without close supervision also may influence the effectiveness of a participative leadership style. ${ }^{13}$ Unfortunately, none of this literature is presented by Marchant, nor does the design or methodology of his study reflect it.

Previous research has not demonstrated that participative management causes high productivity. Most of the research treats small groups with only incidental references to the organization as a whole. Most of the hypotheses regarding the relationships of participative decision making to other organizational variables have been too gross to be proved or disproved.

Marchant defines his purpose as an at- 
tempt "to test the application of Likert's participative management theory within academic libraries."14 Presumably he intends not to reevaluate Likert's theory, but rather to apply it to a library setting. Despite objections in the management literature to the grossness of previous hypotheses, Marchant has not refined his own. He states his principal hypothesis as "the greater the extent to which the professional personnel on the staff are involved in the library's decision making processes, the more effective will be the library's performance."15 Marchant does not define participation in decision making. Whether he means actual decision making, perceived decision making, actual or perceived influence in decision making, increased communication, supportive relationships, or something else remains unclear.

Furthermore, while purporting to apply Likert's theory, Marchant changes Likert's independent variables, adds dependent variables, and entirely omits the intervening variables of the Likert model, inserting his own control variables, some of which are treated as intervening variables in his analysis. (See Figures 1, 2.)

Although Marchant introduces the important variable of job satisfaction, he neglects to cite any literature on the subject, although more than four thousand articles have been published since the 1930s. ${ }^{16}$ Despite the large amount of research, experts still do not agree on the causes of job satisfaction, nor has the question whether job satisfaction influences productivity or vice-versa been answered. ${ }^{17}$ Marchant ignores the controversy.

The omission reflects only one example of the theoretical and empirical research that Marchant might usefully have brought into the library literature. For instance, he might have described the characteristics of the decision making process, defined such concepts as participation, satisfaction, or productivity, or given us a comprehensive review of the literature in one or more areas. Since he fails to do so, his contribution is restricted to the merits of his particular investigation, and even that is seriously flawed for lack of evidence of awareness of previous work.

\section{Measurement}

In his search for ways of measuring independent variables Marchant adopts Likert's "Profile of Organizational Characteristics," which has been validated as a measure of managerial style. ${ }^{18}$ A researcher who borrows another's instrument must either use it in the context of the same theory or establish its validity in the context of his own or different theory; Marchant does neither. Moreover, he simply extracts three of Likert's eighteen questionnaire items and designates them as his "Decision

Simplified Version of the Likert Model

\begin{tabular}{lll}
\hline \hline $\begin{array}{c}\text { Causal Variables } \\
\text { Supportive relationship }\end{array}$ & \multicolumn{1}{c}{$\begin{array}{c}\text { Intervening Variables } \\
\text { Favorable attitudes toward supe- } \\
\text { rior }\end{array}$} & $\begin{array}{l}\text { End-result Variables } \\
\text { Low absence and turnover }\end{array}$ \\
Group decision making & $\begin{array}{l}\text { High confidence and trust } \\
\text { High reciprocal influence } \\
\text { Excellent communication; up, down } \\
\text { and lateral } \\
\text { High peer-group loyalty } \\
\text { High peer performance goals at all } \\
\text { levels re: productivity, quality, } \\
\text { scrap }\end{array}$ & $\begin{array}{l}\text { High productivity } \\
\text { Low scrap }\end{array}$ \\
\hline
\end{tabular}

Source: Likert, The Human Organization, p. 137 
Marchant's Research Model

Independent Variables
1. Decision making
2. Organizational pro-
file

Source: Marchant, "Participative Management ..., p. 51

Figure 2

Making Index." Marchant then uses all eighteen Likert items to form what he calls "Profile Index." Marchant's use of a portion of the Likert questionnaire to measure one variable and then his use of the whole questionnaire, including the extracted portion, to measure another variable seems extraordinarily naive, particularly since Marchant reports the entirely anticipated correlation, .9696.19 This strong relationship merely demonstrates that the "Decision Making Index" and the "Profile Index" are different measures of the same characteristic, managerial style.

Although the validity of the "Decision Making Index" cannot be determined from the single correlation matrix Marchant provides, some assessment of its validity can be made. ${ }^{20}$ First, the average intercorrelations computed for these items in the "Decision Making Index" were computed and compared with the average correlations computed for these same items with the items in the "Profile Index." The within-cluster average (.6966) is higher than the betweencluster average $(.5898)$ as it should be if different constructs are being measured.
As a comparison, two other three-item clusters were extracted from the "Profile Index." The items grouped under the heading, "Leadership process," have an average correlation of .69; they have an average correlation with items in the "Profile Index" of .5588. Three items listed as a "communication process" group have a within-cluster correlation of .64; the average correlation of these items with items in the "Profile Index" is .5735. Although the within-cluster averages are higher than the between-cluster averages for each of these groups, the difference between the correlations is dubious evidence to support the conclusion that more than one construct is being measured. A simple examination of the correlation matrix indicates that the items of the "Decision Making Index" correlate about equally well with each other and with the items in the "Profile Index." It is unlikely that the Likert instrument, as used by Marchant, is measuring more than one construct.

Even if the validity of Marchant's "Decision Making Index" were unassailable, questions would arise as to its reliability. Marchant makes no effort to 
support this characteristic. The demonstration would have been difficult. A three-item scale is rarely reliable, for it requires that all three items measure a single concept. What is considered to be a unidimensional construct, as is assumed by Marchant in the "Decision Making Index," may be two-dimensional or more. Three questions form the index: whether problems are discussed at various levels in the organization, whether decision makers are aware of the problems at the lower levels in the organization, and whether subordinates are able to make their own work decisions. Marchant maintains that each question taps a discrete dimension of the decision making; it is more likely that each question is measuring one aspect of managerial style.

Before the relationships between specific variables can be tested there must be some confidence in the measurement. Since Marchant's "Decision Making Index" inspires little confidence, his conclusions based upon it are correspondingly shaky. Likert validated the "Profile Index" to some extent, making it a more acceptable measure. But it is a measure of the general concept of managerial style, not a measure of participative decision making.

The evidence Marchant uses to assess his dependent variables consists of circulation statistics and responses to a variety of questionnaires. The use of circulation statistics as a measure of library effectiveness has well-known limitations, but the measure has been accepted in the literature as being the best one so far developed. ${ }^{21}$ In the case of the questionnaire measures of satisfaction, faculty evaluation of effectiveness, long-range planning, and uniformity of evaluation, however, Marchant neglects to establish their validity or reliability.

\section{Data Analysis}

Marchant aggregates the data from the individual questionnaires to deter- mine a library's score. The library scores $(\mathrm{N}=22)$ are used in a step-wise regression procedure in order to calculate the proportionate variance in the dependent variables accounted for by the independent and control variables. Variables accounting for the largest proportion of the variance, in most cases, are entered then into a regression equation. The coefficient of determination, $\mathrm{R}^{2}$, is often used as a convenient measure of the success of the regression equation in explaining variations in data, and Marchant adopts it as a measure in his study. However, an increase in $\mathrm{R}^{2}$ can be the result, not of a real significance of the variable added to the model, but of the fact that the number of parameters in the model is getting close to the number of observations..22 Since there are seventeen variables in the Marchant model and twenty-two observations, his reported coefficients of determination must be viewed with caution. Furthermore, in deleting each variable with the highest partial correlation from the subsequent regression equations, Marchant violates the assumption required in regression analysis that the error terms are randomly distributed. A result of this violation can be that variables are retained erroneously in the model and their significance overestimated.

Unfortunately, the table reporting partial correlations between managerial style variables and performance measures in Marchant's article is misleading. It implies that the measures of the relationships between the performance measures and the "Decision Making Index" and "Profile Index," as reported in the table of partial correlations, are independent of the effects of all of the control variables. That is not the case. The partial correlation reported between the "Profile Index" and staff satisfaction was calculated by controlling for ratio of librarians to staff, while the partial correlation between the "Profile Index" and faculty evaluation was cal- 
culated by controlling only for the effect of number of librarians per fulltime student. ${ }^{23}$ Furthermore, book expenditure per student explained the highest proportion of the variance in overall satisfaction when all the control variables and the "Profile Index" were accounted for, but it was omitted when the partial correlation was computed.

While book expenditures per student was identified as the most important variable affecting staff satisfaction, it would be improper to assume that redistributing available funds so as to increase the book budget would result in higher staff satisfaction. The book budget variable stands for the entire wealth factor set of variables, and to divide the budget in some ratio not typical of the libraries studied would insert a condition beyond the predictive capability of the equations.

Further evaluation of the data ... indicated two other important facts. First, variables representing several diverse sources of influence contributed to the cumulative proportionate variance. Second, variables from three different organizational areas were the primary contributors. The first [book expenditure per student] represents the university's financial support. The second [Profile Index] represents managerial style, which is largely determined by library top management. The third [breadth of education] characterizes the staff composition. It is apparent that no one ingredient determines staff satisfaction. ${ }^{24}$

A more serious flaw in Marchant's analysis stems from his use of partial correlations to determine the causal priority of the variables. Partial correlations do not demonstrate causal priority; they assume knowledge of it. Robert Gordon, in his discussion of the partialling fallacy in multiple regression, comments on this directly:

A somewhat more subtle version of the partialling fallacy is likely to be committed in multivariate studies that present all of the possible highest-order partials between each one of a large set of independent variables and the same dependent variable. Apparently, this practice also draws inspiration from Kendall and Lazarsfeld, although the procedures they advocated are actually quite different in logic. Kendall and Lazarsfeld's procedures assume knowledge concerning the presumed causal priority of the variables -they are not intended to provide that knowledge. Roughly, they address the question, "Is variable A causally prior to B, or is it irrelevant?" and not the question, "Is variable A causally prior to B, or is B causally prior to A?" Yet it appears to be the latter question that is being posed when researchers calculate all possible highestorder partials to see which variable will emerge with the largest partial. ...

There is no statistical rule for attributing controlled covariation to the influence of one rather than another of the independent variables, regardless of the disparity in the size between their partial correlations. The question (of whether variable $\mathrm{A}$ is prior to $\mathrm{B}$ or $\mathrm{B}$ is prior to $\mathrm{A}$ ) is simply not answerable by these means. ${ }^{25}$

The Simon-Blalock method for inferring causal relationships from correlation data, which Marchant adopts, involves use of partial correlations in the circumstances where certain combinations of correlations are expected to disappear. ${ }^{26}$ Thus the Simon-Blalock method can be used in some cases to determine which variables might be deleted from a theory. Essential to the appropriate use of the Simon-Blalock method is the existence of a theory. That is, if it is theorized that no relationship exists. between managerial style and size, the correlation between these variables, holding all other variables constant, would be expected to be zero. If the correlation is not zero, the model is adjusted accordingly, and a test of the adjusted model then is made. 
Marchant's Preliminary Model of Causality Explaining Faculty Evaluation (see Figure 3 ) shows faculty evaluation being directly influenced by staff satisfaction and collection size. Variables of managerial style, wealth, and breadth of education (measured by "counting up the number of different disciplines in which a given staff reported having a degree and giving each discipline a weighted value depending upon the highest level of degree reported") explain faculty evaluation indirectly, through their effect upon collection size and staff satisfaction. ${ }^{27}$

Marchant's Preliminary Model

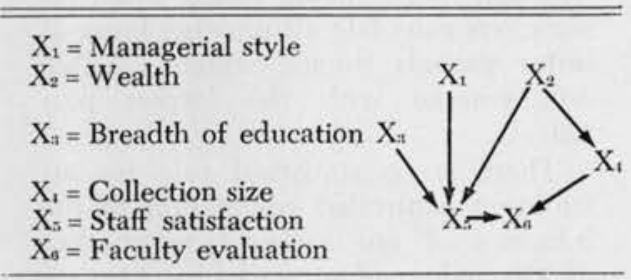

Source: Marchant, "Participative Management ... .," p.54

Figure 3

In this model Marchant assumes that no relationships exist between collection size and staff satisfaction $\left(\mathrm{X}_{4}\right.$ and $\left.\mathrm{X}_{5}\right)$, nor between size and breadth of education or managerial style $\left(\mathrm{X}_{4}\right.$ and $\mathrm{X}_{3}$ or $\mathrm{X}_{1}$ ). However, the simple correlations reported between the "Profile Index" and some measures of size suggest that some relationships between these variables may exist: the correlation between the "Profile Index" and collection size is -.1706, although it is not significant; the correlation between number of librarians (another measure of size) and the "Profile Index" is -.4285 (significant at the .05 level).28 These correlations are interesting in light of Marchant's attempt to control for size by studying Association of Research Libraries' members with collections under three million volumes. However, the size variables are deleted from the data analysis along with several other control variables because of their potentially confounding nature.

Variables related to size and growth of collection and staff are heavily represented [in the group of potentially confounding variables]. It is possible that the managerial style of the larger and older libraries tended to develop when classical theory of administration was current and that smaller libraries tended to be more influenced by later, more participative theories. If this is true, these variables may simply reflect the managerial style which accompanies them. ${ }^{29}$

Aside from the intriguing assumption that managerial style is a static variable, this passage suggests that age and size of library might be causally prior variables, but Marchant dismisses them as mere reflections of managerial style. There is no convincing theoretical argument supporting his exclusion of these variables from his model predicting academic library effectiveness. If several initial assumptions about the ordering of the variables are equally plausible, the statistical techniques used by Marchant provide no basis for deciding among them.

\section{SUMMARY}

Marchant, in his study of the effects of the decision making process on library performance, ignores most of the recent theoretical and empirical research being done on these variables. $\mathrm{He}$ attempts to test hypotheses others were testing in the 1940s and 1950s. His results, like theirs, are inconclusive.

Marchant fails to establish the validity and reliability of his decision making index. Because the only independent variable being measured in his study is the general concept of managerial style, he is unable to test his hypothesis-"the greater the extent to which the professional personnel on the staff are involved in the library's decision making 
processes the more effective will be the library's performance."

Inconclusive though Marchant's study is, he does suggest some variables that might be determinants of satisfaction or dissatisfaction in academic libraries. $\mathrm{He}$ provides no convincing theoretical reasons, however, to explain the inclusion of these variables rather than any others. He bases his choice solely on the results of the step-wise regression procedure, which attributed to them the largest proportion of the explained variance. Unfortunately, the step-wise regression procedure warrants no such conclusions.

Had Marchant presented the assumptions and limitations of Likert's theory and offered empirical evidence that supported or limited the application of this theory to problems of librarianship, library science might have profited. Had Marchant used measures developed by Likert in the context of the same theory or developed valid and reliable measures of his own, his research would have added to the knowledge of the relationships of participation in decision making and library effectiveness. Given the inadequacies of the theoretical development and the invalid measure of decision making, however, the study provides no basis for the generalization that an increase in the library staff's participation in decision making will increase library effectiveness.

\section{REFERENCES}

1. Douglas Waples, "The Graduate Library School at Chicago," Library Quarterly 1:26 (Jan. 1931).

2. Maurice P. Marchant, "Participative Management as Related to Personnel Development," Library Trends 20:48-59 (July 1971).

1, "The Effects of the Decision Making Process and Related Organizational Factors on Alternative Measures of Performance in University Libraries." Unpublished Ph.D. dissertation (Education), University of Michigan, 1970.

3. Rensis Likert, New Patterns of Management (New York: McGraw-Hill Book Co., 1961).

, The Human Organization (New York: McGraw-Hill Book Co., 1967).

4. Nancy C. Morse and Everett Reimer, "The Experimental Change of a Major Organizational Variable," Journal of Abnormal and Social Psychology 52:120-29 (1956).

5. Aaron Lowin, "Participative Decision Making: A Model, Literature Critique, and Prescriptions for Research," Organizational Behavior and Human Performance 3:68106 (1968); and Stephen M. Sales, "Supervisory Style and Productivity: Review and Theory," Personnel Psychology 19: 275-86 (1966).

6. Robert C. Day and Robert L. Hamblin, "Some Effects of Close and Punitive Styles of Supervision," American Journal of Sociology 6: :499-510 (1964). Marvin E. Shaw,
"A Comparison of Two Types of Leadership in Various Communication Nets," Journal of Abnormal and Social Psychology 50:127-34 (1955).

7. Harold G. McCurdy and Herbert W. Eber, "Democratic versus Authoritarian: A Further Investigation of Group Problem-Solving," Journal of Personality 22:258-69 (1953). Stephen M. Sales, "A Laboratory Investigation of the Effectiveness of Two Industrial Supervisory Dimensions," Unpublished M.S. Thesis, Cornell University (1964). Paul Spector and Barbara Suttell, An Experimental Comparison of the Effectiveness of Three Patterns of Leadership Behavior. (Washington, D.C.: American Institute for Research, 1957).

8. Reed M. Powell and John L. Schlacter, "Participative Management-a Panacea?" Academy of Management Journal 14:16573 (June 1971).

9. Alex Carey, "The Hawthorne Studies: A Radical Criticism," American Sociological Review 32:403-16 (1967). Abraham K. Korman, "Consideration," "Initiating Structure," and "Organizational Criteria-a Review," Personnel Psychology 19:349-61 (1966). Victor H. Vroom, Work and Motivation (New York: J. Wiley, 1964).

10. Aaron Lowin and James R. Craig," The Influence of Level of Performance on Managerial Style: An Experimental Object-Lesson in the Ambiguity of Correlational Data," Organizational Behavior and $\mathrm{Hu}$ - 
man Performance 3:440-58 (1968).

11. George Franklin Farris, "A Causal Analysis of Scientific Performance," Unpublished Ph.D. dissertation, University of Michigan (1966).

12. Victor H. Vroom and Floyd C. Mann, "Leader Authoritarianism and Employee Attitudes," Personnel Psychology 13:12539 (1960). John R. P. French, Jr. et al., "An Experiment on Participation in a Norwegian Factory," Human Relations 13:3-19 (1960). Uriel G. Foa, "Relation of Workers Expectation to Satisfaction with Supervisor," Personnel Psychology 10:161-68 (1957). Cecil A. Gibb, "Leadership," in The Handbook of Social Psychology, ed. by Gardner Lindzey and Elliot Aronson. (Reading, Mass.: Addison-Wesley, 1969). Martin Patchen, "Supervisory Methods and Group Performance Norms," Administrative Science Quarterly 7:275-94 (1962). Donald C. Pelz, "Influence: A Key to Effective Leadership in the First Line Supervisor," Personnel 29:209-17 (1952).

13. Alan C. Filley and Robert J. House, Managerial Process and Organizational Behavior (Glenview, Ill.: Scott, Foresman, 1969).

14. Marchant, "Participative Management ...," p. 51 .

15. Marchant, "The Effects of the Decision Making Process ....," p. 26.

16. Edwin A. Locke, "What Is Job Satisfaction?" Organizational Behavior and Human
Performance 4:309-36 (1969).

17. Donald P. Schwab and Larry L. Cummings, "Theories of Performance and Satisfaction: A Review," Industrial Relations 9: 408-30 (Oct. 1970).

18. Marchant, "Participative Management ...,", p. 52. Likert, Human Organization. p. 11722.

19. Marchant, "The Effects of the Decision Making Process ....," p. 132.

20. Ibid., p. 298.

21. Leon Carnovsky, "Survey of the Use of Library Resources and Facilities," in Library Surveys, ed. by Maurice F. Tauber and Irlene Roemer Stephens. (New York: Columbia University Press, 1967).

22. N. R. Draper and H. Smith, Applied Regression Analysis (New York: J. Wiley, 1966).

23. Marchant, "The Effects of the Decision Making Process ....," p. 157 and p. 250.

24. Ibid., p. 158.

25. Robert A. Gordon, "Issues in Multiple Regression," American Journal of Sociology 73:592-616 (March 1968).

26. Herbert A. Simon, Models of Man (New York: J. Wiley, 1957); Hubert M. Blalock, Jr., Causal Inferences in Nonexperimental Research (Chapel Hill: University of North Carolina Press, 1964).

27. Marchant, "The Effects of the Decision Making Process ..., ," p. 114.

28. Ibid., p. 134.

29. Ibid., p. 136. 